\title{
Where Are Your Thoughts? On the Relationship between Technology Use and Mind Wandering
}

\author{
Frederike Marie Oschinsky \\ University of Siegen, Germany \\ frederike.oschinsky@uni-siegen.de \\ Nina Ressel \\ University of Siegen, Germany \\ nina.ressel@student.uni-siegen.de
}

\author{
Michael Klesel \\ University of Siegen, Germany and \\ University of Twente, The Netherlands \\ $\underline{\text { michael.klesel@uni-siegen.de }}$
}

\author{
Bjoern Niehaves \\ University of Siegen, Germany \\ bjoern.niehaves@uni-siegen.de
}

\begin{abstract}
Mind wandering is an important brain activity that fosters creativity and productivity. Research suggests that individuals spend up to $50 \%$ of their waking time thinking about things that are unrelated to the present situation or task. Previous literature has acknowledged the importance of mind wandering in technology-related contexts by investigating its mediating role between task and individual performance. In this study, we go one step further and investigate the direct relationship between technology use and mind wandering. In particular, we investigate if different types of technology use (hedonic use vs. utilitarian use) have an impact on mind wandering. Results from a factorial survey study $(n=90)$ suggest that there is a significant difference between hedonic use and utilitarian use when it comes to mind wandering. Based on these insights, we discuss the role of mind wandering for IS research and potentials for future research.
\end{abstract}

\section{Introduction}

Every day, our thoughts trail off up to $50 \%$ of our waking time [55]. This mind wandering occurs in various situations such as driving a car, doing work-related tasks, or reading a book. Smallwood and Schooler's [55] compelling review shows, that despite the high price of losing touch with the environment, there are distinct benefits letting your mind wander. For example, research shows that mind wandering enhances creativity [7] or contributes to better productivity and problem solving skills $[55,61]$. Therefore, the concept of mind wandering is important for many fields of research and for practice

Similarly, it is most likely that our mind wanders when using technology. Since technology is increasingly becoming a part of our daily lives, this aspect becomes more relevant. Today, technology is used for both hedonic purposes (e.g., gaming or social media) and utilitarian purposes (e.g., E-mails or scheduling). In fact, current studies suggest that our use behavior is intense. In total, an average person uses her mobile phone for various purposes for about 150 minutes per day [cited in 59]. Hence, mind wandering is increasingly relevant when it comes to technology use.

Information Systems (IS) research has recently acknowledged the relevance of mind wandering and has started to investigate technology-related mind wandering (e.g., [61,70]). However, it has been primarily used as a moderating effect. With the increasing use of technology in various domains (e.g., private or organizational domain) and based on various systems (e.g., hedonic or utilitarian), there is reason to believe that technology use also has a direct effect on mind wandering. Hedonic usage is pleasure-oriented and provides self-fulfilling value to the user [31]. On the contrary, utilitarian usage is productivity-oriented and provides instrumental value (ibid.). Since hedonic usage is closely connected to leisure activities and fun, a user is not tied to instrumental goals. Hence, we expect hedonic usage to lead to a higher level of mind wandering. This is also in line with previous literature demonstrating that different forms of technology use lead to different outcomes (e.g., [71]). Consequently, we argue that it is of crucial importance to further investigate a direct relationship between technology use and mind wandering. Through an experimental design with 90 participants, we provide evidence that the use of a specific type of system (hedonic / utilitarian [31]) has an impact on the degree of mind wandering.

Our contributions are likewise theoretical and practical. From a theoretical perspective, we contribute to existing literature on technology use by clarifying the relationship between different types of technology and mind wandering. We approach this topic in an 
exploratory manner and draw a link between psychological, neuroscientific and IS research. For practitioners, we provide further insights on the role of mind wandering in terms of technology use which in turn can be used to enhance productivity and creativity for knowledge workers. Moreover, our work can be of guidance when it comes to technology design that seeks to enhance creativity and problem-solving. In addition, we encourage future research to minimize disruption [23] and to focus on potential negative consequences regarding technology use.

To address our objective, this paper is organized as follows: First, we investigate the literature on mind wandering in psychology, neuroscience, and IS research. Next, we propose our research model that hypothesizes that there are differences in the relationship between use and mind wandering. Then, we describe our research methodology and present the results. We conclude with a discussion of the results and suggest potential areas for future research.

\section{Theoretical Background}

Studying daydreaming has ignited research on the exploration of the mind's capacity to wander [1-8], yielding in a new research area on mind wandering [9-15]. This increasing interest was accompanied by new measurement techniques. For instance, functional magnetic resonance imaging (fMRI) visualizes how the default mode network (DMN) engages during mind wandering [16-19]. Consequently, various neuroscientific studies have emerged [14,21,30]. As a consequence, psychologists nowadays agree that unconstrained mental processes are the norm rather than the exception: Between one third and half of our daily mental activity is unrelated to our external environment and off-task [55]. Mind wandering is commonly defined as " $a$ shift of executive control away from a primary task to the processing of personal goals" [56:946] and as the mind's capacity to move away aimlessly from external happenings and tasks [24].

The current state of research illustrates that mind wandering mostly occurs during the resting state, in non-demanding circumstances and during task-free activity $[10,58]$. Attention drifts from a current task to mental content $[44,49,50]$ and shifts from an external thought generated by the environment to an internal, task-unrelated idea [26]. Such a state of decoupled attention is characterized by thinking exclusively about internal notions and feelings and by the temporal inability to process external information [53].

Mind wandering is often perceived as cumbersome and prejudicial $[53,57]$. First, it is enhanced by stress as well as alcohol and substance abuse [20,48,54].
Second, it stands for a lack of awareness and consequently a cause of poor performance, errors, disruption, disengagement, carelessness and unhappiness $[8,19,73]$. For example, research shows that it becomes apparent in situations where it is not necessarily desirable, for example, when driving a car [8,73]. Nevertheless, mind wandering also correlates with creativity and a positive mood $[7,22,41,70]$. It helps give significance to personal experiences and facilitate future planning [41,55]. Furthermore, it can provide mental breaks and helps relieve boredom. In summary, literature shows that mind wandering seems to offer both risks and opportunities.

In IS research, the topic of mind wandering has mainly been neglected notwithstanding its increasing relevance in a time where we are always connected and online without switching to effortless thinking. Always being alert was found to increase psychological distress [9], anxiety and insomnia [32], work overload and reduced organizational commitment $[64,65,66,67]$. Although IS research offers established knowledge on task performance (e.g., $[16,31,12,43])$ and attentional shifts (e.g., [60]), it lacks exhaustive findings on the correlation between technology use and task unrelated thought [61]. Thus, various authors publishing in high-ranking journals have called for a more fine grained view on both technology use behavior and mind activity in IS [17,55,61,62]. Assessing the state of research shows that there has been both an increasing interest and an important gap to fill.

In IS research, Sullivan et al. suggest mind wandering to be both task-related and technology-related, defining technology-related mind wandering as "taskunrelated thought which occurs spontaneously and the content is related to the aspects of computer systems" [61:4]. Wati and her colleagues, who introduced the concept of mind wandering to our domain, devote their pertinent research to this area of research, as they demonstrate that user performance is influenced by an individual's focus ability and mind wandering [70]. Having assessed different levels of task complexity, the authors call for taking into account the characteristics of technology use in greater detail in the future. At a later stage, the authors focus on the content of thought during mind wandering technology-related and non-technology-related settings [61]. They provide further empirical evidence that mind wandering moderates the relationship between on-task thought with creativity and knowledge retention. Their research repeatedly demonstrates that mind wandering has a significant impact on crucial aspects such as task performance.

Although previous research acknowledged the role of the mind and its impact on outcome variables such as performance, there is little research available that 
investigates the role of IT mind wandering. Against this background, we seek to shed further light on this research area in order to understand the relationship between technology use and IT mind wandering.

\section{Research Model}

External variables such as technology characteristics or use behavior have a significant impact on outcome variables such as mind-related concepts (e.g., [11]). Therefore, a relationship between technologyrelated aspects and mind wandering is most likely. Since current literature primarily investigated the indirect effects of mind wandering on its outcomes, we focus on the direct effects of use behavior on the mind wandering experience itself. In doing so, we aim to a better understand mind wandering in the context of IS.

There are two important types of systems (e.g., [38]). Literature on technology acceptance [15,69] widely focuses on utilitarian use to shed light on individual factors that influence technology use and adoption. With the rise of mobile technologies, hedonic factors have become increasingly important. This is most notable with regard to social media and mobile games. To that end, previous literature suggests that hedonic use differs from utilitarian use. For instance, Lowry et al. [38] indicate that cognitive absorption is more important when it comes to hedonic use. In the context of the problem at hand, we argue that the use of a hedonic system is expected to be a strong determinant of mind wandering, because it is closely related to activities we do in our leisure time. Here, people are primarily interested to enjoy using a system instead of following instrumental goals. Moreover, hedonic usage can be considered as an almost non-demanding and effortless activity, and consequently invite the user to let her mind wander. Thus, we assume that the type of system (hedonic / utilitarian) and its corresponding use affects the degree of mind wandering. Against this background, we propose the following hypothesis $(\mathrm{H})$.

$\mathrm{H}$ : $\quad$ The use of hedonic systems leads to a higher degree of mind wandering compared to the use of utilitarian systems.

\section{Methodology}

Method Selection. To explore variances in terms of mind wandering, we used an experimental design with a strong internal consistency. In particular, we applied a factorial survey methodology [47] that has been successfully applied in similar research endeavors (e.g., [68]).
Experimental Procedure. The scenario-based experiment covered four phases: First, participants were informed about the general setting and the goal of the study. Second, the circumstances and initial situation were presented by a short description underlined with an appealing image. Third, the participants were randomly assigned to one of four scenarios and watched a video (about 30 seconds long). Each scenario had been recorded on a mobile phone and followed the same procedure. To ensure a high level of involvement, we invited the participants to refer to the following situation based on what kind of technology they use on a daily basis (e.g., smartphone, tablet, or laptop). The participants were asked to fill out a questionnaire at the end.

Context. We introduced the participants to a workplace situation around 10 o'clock in the morning where employees usually enjoy a coffee break. Since a previous task took longer than expected, the participant started her/his break a little later and started paying attention to her/his mobile phone.

Experimental scenarios. After the contextual introduction, each participant watched one of the following videos, which are described briefly in the following (more details for each scenario, including screenshots of the movie, are attached in the appendix):

Scenario 1 ("Gaming"): a common type of hedonic use of technology is playing (mobile-) games (e.g., [37]). To mimic this type of use, we showed the game "Froggy Jump" by Invictus Games Limited. It is a popular mobile game where the goal to navigate a jumping frog through obstacles to gain points.

Scenario 2 ("Facebook"): another important type of hedonic use relates to social media use. To imitate this type, we selected Facebook and showed a video where the participant navigates quickly through commercials, comments, and postings.

Scenario 3 ("Booking"): to represent utilitarian use of technology, we provided a video that shows a booking process for a railway ticket. Here, the participant saw subsequent steps of booking a ticket, starting with entering the point of departure and destination and ending with paying and skipping the tickets.

Scenario 4 ("E-mail"): finally, to represent a second example of utilitarian use, we showed a video of writing an E-mail to a professor to register for a workshop. In this scenario, the participant saw a complete composition of a short E-mail that was sent to the professor at the end.

Participants. We collected data from 105 participants. We included complete data and excluded observations with less than 3-minutes participation time resulting in 90 observations in total. The participants average age was $29.72(S D=12.10), 48$ were male 
$(53.3 \%), 42$ female $(46.7 \%)$, and have an average tenure of 8.37 years $(S D=10.26)$.

Measurement. Mind wandering is an internal mental experience and can be measured based on self-reports [55]. In the literature, mind wandering is often measured by means of a single item, which prevents a further analysis of psychometric attributes. Since there are several multi-measures available $[42,70,61,51]$ we selected four items (c.f. Table 1). To ensure content validity, we translated each item from English to the participants' first language and back. We investigated the internal consistency (based on Cronbach's alpha), which suggests a good reliability $(\alpha=.81)$. We conclude that the measurement instrument is well suited for the subsequent analysis.

Table 1. Measurement Items

\begin{tabular}{ll}
\hline & In this situation... \\
\hline WAND1 & my mind wandered. \\
\hline WAND2 & $\begin{array}{l}\text { I thought about something, which } \\
\text { was not related to the situation. }\end{array}$ \\
\hline WAND3 & I was daydreaming. \\
\hline WAND4 & I did not concentrate on the situation. \\
\hline
\end{tabular}

Convergent and discriminant validity. In order to assess the convergent and discriminant validity, we investigated the correlations matrix between the mind wandering items and the control variables (age, gender, job, tenure). As shown in Table 2, there are significant correlations between all items that measure mind wandering and non-significant correlation between the control variables and mind wandering. Therefore, we assume a sufficient degree of convergent and discriminant validity. Note, that there are significant correlations between age and tenure as well as job and tenure, which is, however, common for this set of demographic variables. We also investigated the Variance Inflation Factor (VIF). Since all values are below the threshold of $10(1.1<\mathrm{VIF}<5.7)$ [29], we conclude that multicollinearity is not a major issue here.

Manipulation Checks. We measured perceived usefulness as suggested by Agarwal and Karahanna [1] to check if our intended manipulation (i.e., hedonic use versus utilitarian use) was successful. Sum scores were computed to carry out an analysis of variance (ANOVA) between all groups. The results indicate that there is a significant variation in terms of perceived usefulness $F(3,82)=7.337, p<.000$. A post hoc analysis (Tukey's HSD) shows that all manipulations worked as intended.
Table 2. Correlation Matrix

\begin{tabular}{cccccccc} 
& 1 & 2 & 3 & 4 & 5 & 6 & 7 \\
\hline 1 & - & & & & & & \\
2 & -0.04 & - & & & & & \\
3 & -0.18 & 0.14 & - & & & & \\
4 & $\mathbf{0 . 9 0}$ & -0.16 & $-0.26^{*}$ & - & & & \\
5 & -0.13 & 0.05 & -0.17 & -0.17 & - & & \\
6 & 0.01 & 0.05 & -0.19 & -0.02 & $\mathbf{0 . 7 2}$ & - & \\
7 & -0.14 & 0.08 & -0.09 & -0.16 & $\mathbf{0 . 8 3}$ & $\mathbf{0 . 5 9}$ & - \\
8 & 0.17 & 0.10 & -0.11 & 0.12 & $0.29^{* *}$ & $\mathbf{0 . 4 0}$ & $0.32^{* *}$ \\
\hline 1. & & & & & & \\
\hline
\end{tabular}

1. Age, 2. Gender, 3. Job, 4. Tenure,

5. WAND1, 6. WAND2, 7. WAND3, 8. WAND4

Note: $\mathbf{p}<.001, * * \mathrm{p}<.01 ; * \mathrm{p}<.05$

Scenario 1 ("Gaming”) differs significantly from scenario 3 ("Booking") and scenario ("E-Mail"). Scenario 2 ("Facebook") differs significantly from scenario 3 ("Booking") and scenario 4 ("E-Mail"). Therefore, we conclude that all scenarios reflect utilitarian and hedonic use as intended. An overview is given in Table 3.

Table 3. Post Hoc Analysis Perceived Usefulness

\begin{tabular}{lccccccc}
\hline & & & \multicolumn{4}{c}{$\begin{array}{c}\text { Tukey's HSD } \\
\text { Comparisons }\end{array}$} \\
\cline { 6 - 9 } Scenario & $n$ & $\mathrm{M}$ & $S D$ & $(1)$ & $(2)$ & (3) \\
\hline (1) Gaming & 22 & 2.39 & 1.41 & & & \\
\hline (2) Facebook & 25 & 2.73 & 1.53 & .852 & & \\
\hline (3) Booking & 27 & 3.78 & 1.35 & .007 & .055 & \\
\hline (4) E-Mail & 16 & 4.27 & 1.61 & .001 & .008 & .716 \\
\hline
\end{tabular}

\section{Results}

We carried out an analysis of covariance (ANCOVA) to identify group differences and possible covariates at the same time. For that purpose, sum scores were used for mind wandering. The results are summarized in Table 1. The results indicate a significant variation among the scenarios, $\mathrm{F}(3,82)=5.769, \mathrm{p}=$ 0.001. Moreover, this shows that, apart from "job", there is no significant influencing factor. 
Table 4. ANCOVA Results

\begin{tabular}{lccc} 
Variable & $d f$ & $\mathrm{~F}$ & $P$ \\
\hline Scenario & 3 & 5.769 & $.001^{* *}$ \\
Age & 1 & 0.934 & .336 \\
Gender & 1 & 0.615 & .434 \\
Job & 1 & 5.012 & $.028^{*}$ \\
Tenure & 1 & 1.112 & .295 \\
\hline
\end{tabular}

Note: ${ }^{* *} \mathrm{p}<.01 ;{ }^{*} \mathrm{p}<.05$

Since the overall test is significant, we investigated the descriptive statistics and carried out a post hoc analysis using Tukey's HSD. The post hoc analysis indicates that group 1 ("Gaming") differs significantly $(\mathrm{p}<.05)$ from group 4 ("E-mail”). Moreover, we found a significant difference $(\mathrm{p}<.05)$ between group 2 ("Facebook") and group 3 ("Booking") and a significant difference $(\mathrm{p}<.01)$ between group 2 ("Facebook") and group 4 ("E-Mail"). All other groups, are somewhere in the middle. An overview of the post hoc analysis is presented in Table 5 and in Figure 1.

Table 5. Post Hoc Analysis Mind Wandering

\begin{tabular}{|c|c|c|c|c|c|c|}
\hline \multirow[b]{2}{*}{ Group } & \multirow[b]{2}{*}{$n$} & \multirow[b]{2}{*}{ M } & \multirow[b]{2}{*}{$S D$} & \multicolumn{3}{|c|}{$\begin{array}{l}\text { Tukey's HSD } \\
\text { Comparisons }\end{array}$} \\
\hline & & & & (1) & (2) & (3) \\
\hline (1) Gaming & 22 & 4.06 & 1.37 & & & \\
\hline (2) Facebook & 25 & 4.45 & 1.52 & .806 & & \\
\hline (3) Booking & 27 & 3.19 & 1.69 & .194 & .017 & \\
\hline (4) E-Mail & 16 & 2.73 & 1.28 & .042 & .003 & .765 \\
\hline
\end{tabular}

\section{Discussion}

This study seeks to shed further light on the relationship between technology use and mind wandering. Therefore, it expands on previous efforts that have investigated the intermediate role of mind wandering and put emphasis on wandering in terms of hedonic and utilitarian use of technology.

Discussion of results. In most cases, the results confirm our proposed hypothesis. In fact, three out of four group-wise comparisons are significant. In terms of the considered scenarios, the results indicate that writing an E-Mail shows the lowest level of mind wandering $(\mathrm{M}=2.73, \mathrm{SD}=1.28)$. In contrast to the booking scenario $(\mathrm{M}=3.19, \mathrm{SD}=1.69)$, this difference is significant. It seems that the autonomy that is related to a task may have a pertinent role. This insight is related to previous findings that indicate that the complexity of a task significantly impacts mind wandering. Assuming that writing an E-mail allows a high degree of freedom compared to a structured booking process, it is also more complex to fulfill this task.

Both hedonic scenarios do not differ significantly. Still, we observe a difference in a direct comparison with scenario 3 ("Booking") because only Facebook use differs significantly. We conclude that other factors such as the degree of cognitive absorption may also play a major role when it comes to mind wandering. Specifically, the results may indicate that playing a game requires the same degree of engagement or cognitive focus as a booking process, which in turn might explain a non-significant relationship between those groups.

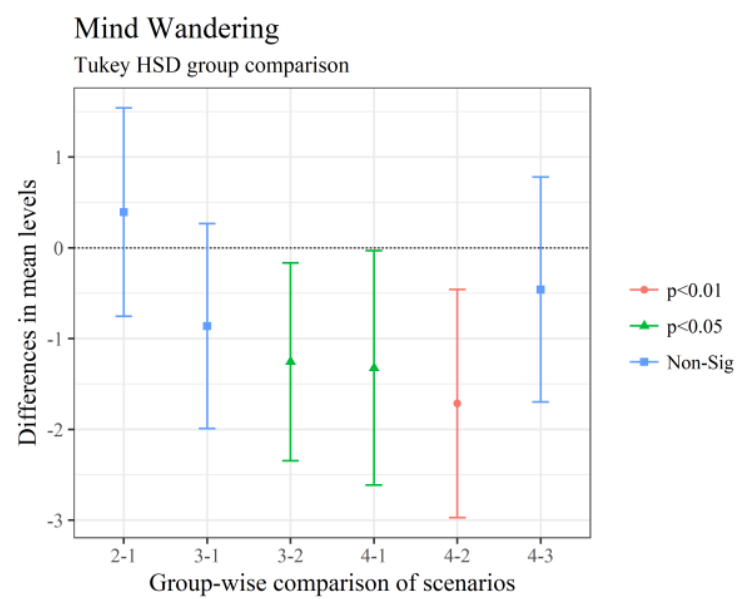

Figure 1. Group Differences

Implications for theory. Despite the fact that individuals spend up to $50 \%$ of their waking time letting their mind wander, IS research has only spent little effort acknowledging related effects. Therefore, future research can benefit from this exploratory study as a point of departure for further research on mind wandering. In specific, it provides initial evidence that the use of hedonic systems has a higher impact on mind wandering which in turns open the door for further research that can investigate what type of aspects are most relevant in this regard. Moreover,, with a rising interest in IT mindfulness [17,62,63], IS research can benefit from a more holistic perspective on mental activities. As neuro science suggests that the state of mind is likely to have an affect technology-related behavior, the field of NeuroIS opens the door for future research in various directions $[18,46]$. 
This research suggests that technology-related variables such as technology use or a technological artifact have a significant impact on the state of mind and can thus be understood as an important stimulus of mind activity. Distinguishing between hedonic systems and utilitarian systems, our research also contributes to existing literature on technology use and user acceptance. The increasingly hedonic nature of information systems, where the majority of websites and applications aim at being user-friendly, implies the need to also assess a person's motivation not to use a hedonic system [31] or the danger of using hedonic systems in a dysfunctional manner [59]. With the ubiquity of technology, many potential drawbacks including addiction, work overload, disrupted work-life-balance, technostress can occur (e.g., [64,6,72,59]). Therefore, it remains important to examine different facets of the nature of technology use and the implication for individual well-being and productivity.

For research on 'the dark side' of technology on the other hand, mind wandering might also be an important aspect to consider because it allows individuals to detach and 'dream away' from (possible stressful) situations. Even though this might only happen for a limited amount of time, it might support buffering negative events. Moreover, by following a balanced view on both the benefits of technology use and the implications of mind wandering, this paper can help understand how to maximize positive results while reducing negative consequences of both phenomena at the same time. Those insights offer guidance for academia, managers, organizations, and society.

In summary, we put forward good reasons to further investigate the role of mind wandering in relation to technology. Based on this argument, we also offer new insights into how a primarily psychological state is related to IS. Based on our experimental study, we present implications on how the mind drifts away from current situations and tasks and present a point to connect alternative scenarios or replications near the mark. Considering mind wandering research, we also find links to the dual system theory, which is at the core of Kahneman's canonical work on "thinking fast and slow" [33]. In particular, mind wandering can be related to System 1 (automated, effortless thinking) in contrast to System 2 (controlled and focused thinking).

Implications for design. Although this piece of research primarily seeks to understand the relationship between technology use and mind wandering, it is also beneficial to design-related research. Most importantly, it indicates that, apart from the characteristic of a specific task, the design and the corresponding use experience might also affect mind wandering. Specifically, we assume that specific designs or design elements invite individuals to let their thoughts drift off.
Consequently, an IT artifact designed for utilitarian purposes (e.g., an Enterprise Resource Planning system) should consider this aspect in order to decrease mind wandering because it negatively impacts productivity $[70,61]$. In contrast, artifacts that are designed to accelerate creativity should in turn stimulate mind wandering because it significantly increases creativity [7]. We thus encourage future research to develop and test design theories in light of mind wandering.

Implications for practice. Our research has also implications for practice. It highlights the relationship between use behavior and mind wandering. Therefore, organizations that seek to enhance mind wandering (e.g., creative environments) might investigate where specific types of use behavior might be useful. In contrast, domains in which mind wandering interferes with productivity, hedonic-based use behavior could be reduced. Within the context of managing and using IT, mind wandering has an impact on performance and is consequently important to consider when designing IT artifacts.

\section{Limitations and Outlook}

This study comes with some limitations that open the door for future research. First, since we investigate the relationship between use behavior and mind wandering, we do not distinguish between task-related wandering and technology-related wandering [61]. Hence, future research could include this. Second, structural relationships, i.e., the impact of mind wandering on enjoyment or creativity, are not included here. Third, environmental factors including job characteristics may also play a crucial role when it comes to mind wandering. For example, individuals who are involved in very intense professions may have a more limited opportunity for mind wandering than others. In contrast, individuals who are involved in scheduled work may perceive a higher level of mind wandering. Finally, future research should triangulate the measurement of IT mind wandering using additional techniques such as eye tracking, or brain imaging. Therefore, research on Neuro IS $[18,46]$ could provide further insights into the role of mind wandering.

\section{Acknowledgements}

This paper was written as part of the research project SUGAR (promotional reference 02L14A011), which is funded by the German Federal Ministry of Education and Research (BMBF). 


\section{References}

[1] Agarwal, R. and Karahanna, E. Time Flies When You're Having Fun: Cognitive Absorption and Beliefs about Information Technology Usage. MIS Quarterly 24, 4 (2000), 665.

[2] Andrews-Hanna, J.R., Smallwood, J., and Spreng, R.N. The Default Network and Self-Generated Thought: Component Processes, Dynamic Control, and Clinical Relevance. Annals of the New York Academy of Sciences 1316, (2014), 29-52.

[3] Antrobus, J.S., Antrobus, J.S., and Singer, J.L. Eye Movements Accompanying Daydreaming, Visual Imagery, and Thought Suppression. Journal of Abnormal Psychology 69, (1964), 244-252.

[4] Antrobus, J.S., Coleman, R., and Singer, J.L. Signal-detection Performance by Subjects Differing in Predisposition to Daydreaming. Journal of Consulting Psychology 31, 5 (1967), 487-491.

[5] Antrobus, J.S., Singer, J.L., Goldstein, S., and Fortgang, M. Mindwandering and Cognitive Structure. Transactions of the New York Academy of Sciences 32, 2 (1970), 242252.

[6] Ayyagari, R., Grover, V., and Purvis, R. Technostress: Technological Antecedents and Implications. MIS Quarterly 35, 4 (2011), 831-858.

[7] Baird, B., Smallwood, J., Mrazek, M.D., Kam, J.W.Y., Franklin, M.S., and Schooler, J.W. Inspired by Distraction: Mind Wandering Facilitates Creative Incubation. Psychological Science 23, 10 (2012), 1117-1122.

[8] Baldwin, C.L., Roberts, D.M., Barragan, D., Lee, J.D., Lerner, N., and Higgins, J.S. Detecting and Quantifying Mind Wandering during Simulated Driving. Frontiers in Human Neuroscience 11, (2017), 406.

[9] Beranuy, M., Oberst, U., Carbonell, X., and Chamarro, A. Problematic Internet and Mobile Phone Use and Clinical Symptoms in College Students: The Role of Emotional Intelligence. Computers in Human Behavior 25, (2009), 1182 .

[10] Buckner, R.L. and Vincent, J.L. Unrest at Rest: Default Activity and Spontaneous Network Correlations. NeuroImage 37, 4 (2007), 1091-1099.

[11] Burton-Jones, A. and Hubona, G.S. The Mediation of External Variables in the Technology Acceptance Model. Information \& Management 43, 6 (2006), 706-717.

[12] Burton-Jones, A. and Straub, D.W. Reconceptualizing System Usage: An Approach and Empirical Test. Information Systems Research 17, 3 (2006), 228-246.
[13] Choi, H., Geden, M., and Feng, J. More Visual Mind Wandering Occurrence During Visual Task Performance: Modality of the Concurrent Task Affects How the Mind Wanders. PLOS ONE 12, 12 (2017), e0189667.

[14] Christoff, K., Irving, Z.C., Fox, K.C.R., Spreng, R.N., and Andrews-Hanna, J.R. Mind-wandering as Spontaneous Thought: A Dynamic Framework. Nature Reviews Neuroscience 17, 11 (2016), 718-731.

[15] Davis, F.D. Perceived Usefulness, Perceived Ease of Use, and User Acceptance of Information Technology. MIS Quarterly 13, 3 (1989), 319-340.

[16] Delone, W.H. and McLean, E.R. The DeLone and McLean Model of Information Systems Success: A TenYear Update. Journal of Management Information Systems 19, 4 (2003), 9-30.

[17] Dernbecher, S. and Beck, R. The Concept of Mindfulness in Information Systems Research: a Multi-Dimensional Analysis. European Journal of Information Systems 26, 2 (2017), 121-142.

[18] Dimoka, A., Pavlou, P.A., and Davis, F.D. NeuroIS: The Potential of Cognitive Neuroscience for Information Systems Research. Information Systems Research 22, 4 (2011), 687-702.

[19] Drescher, L.H., Van den Bussche, E., and Desender, K. Absence without leave or leave without absence: Examining the interrelations among mind wandering, metacognition and cognitive control. PLOS ONE 13, 2 (2018), e0191639.

[20] Epel, E.S., Puterman, E., Lin, J., Blackburn, E., Lazaro, A., and Mendes, W.B. Wandering Minds and Aging Cells. Clinical Psychological Science 1, 1 (2013), 7583.

[21] Fox, K.C.R., Spreng, R.N., Ellamil, M., AndrewsHanna, J.R., and Christoff, K. The Wandering Brain: Metaanalysis of Functional Neuroimaging Studies of Mind-wandering and Related Spontaneous thought Processes. NeuroImage 111, (2015), 611-621.

[22] Franklin, M.S., Mrazek, M.D., Anderson, C.L., Smallwood, J., Kingstone, A., and Schooler, J.W. The Silver Lining of a Mind in the Clouds: Interesting Musings are Associated with Positive Mood while Mind-wandering. Frontiers in Psychology 4, (2013).

[23] Galluch, P.S., Grover, V., and Thatcher, J.B. Interrupting the Workplace: Examining Stressors in an Information Technology Context. Journal of the Association for Information Systems 16, 1 (2015), 1-47. 
[24] Giambra, L.M. Task-unrelated-thought Frequency as a Function of Age: a Laboratory Study. Psychology and Aging 4, 2 (1989), 136-143.

[25] Giambra, L.M. The Influence of Aging on Spontaneous Shifts of Attention from External Stimuli to the Contents of Consciousness. Experimental Gerontology 28, 4-5 (1993), 485-492.

[26] Giambra, L.M. A Laboratory Method for Investigating Influences on Switching Attention to Task-unrelated Imagery and Thought. Consciousness and Cognition 4, 1 (1995), 1-21.

[27] Gilbert, S.J., Dumontheil, I., Simons, J.S., Frith, C.D., and Burgess, P.W. Comment on "Wandering Minds: the Default Network and Stimulus-independent Thought." Science 317, 5834 (2007), 43.

[28] Gruberger, M., Ben-Simon, E., Levkovitz, Y., Zangen, A., and Hendler, T. Towards a Neuroscience of Mind-Wandering. Frontiers in Human Neuroscience 5, (2011).

[29] Hair, J.F., Black, W.C., Babin, B.J., and Anderson, R.E. Multivariate Data Analysis. Pearson, Harlow, 2014.

[30] Hawkins, G.E., Mittner, M., Boekel, W., Heathcote, A., and Forstmann, B.U. Toward a Model-based Cognitive Neuroscience of Mind Wandering. Neuroscience 310, (2015), 290-305.

[31] van der Heijden, H. User Acceptance of Hedonic Information Systems. MIS Quarterly 28, 4 (2004), 695-704.

[32] Jenaro, C., Flores, N., Gómez-Vela, M., González-Gil, F., and Caballo, C. Problematic Internet and Cell-phone Use: Psychological, Behavioral, and Health Correlates. Addiction Research \& Theory 15, 3 (2007), 309-320.

[33] Kahneman, D. Thinking, Fast and Slow. Penguin, London, 2011.

[34] Kane, M.J. and McVay, J.C. What Mind Wandering Reveals About Executive-Control Abilities and Failures. Current Directions in Psychological Science 21, 5 (2012), 348-354.

[35] Klinger, E. Fantasy Need Achievement as a Motivational Construct. Psychological Bulletin 66, 4 (1966), 291308.

[36] Klinger, E. Models, Context, and Achievement Fantasy: Parametric Studies and Theoretical Propositions. Journal of Personality Assessment 37, 1 (1973), 25-47.

[37] Lin, H.-H., Wang, Y.-S., and Chou, C.-H. Hedonic and Utilitarian Motivations for Physical Game Systems Use Behavior. International Journal of Human-Computer Interaction 28, 7 (2012), 445-455.
[38] Lowry, P.B., Gaskin, J., Twyman, N., Hammer, B., and Roberts, T. Taking "Fun and Games" Seriously: Proposing theHedonic-Motivation System Adoption Model (HMSAM). Journal of the Association for Information Systems 14, 11 (2013), 617-671.

[39] McKiernan, K.A., D’Angelo, B.R., Kaufman, J.N., and Binder, J.R. Interrupting the "Stream of Consciousness": an fMRI Investigation. NeuroImage 29, 4 (2006), $1185-1191$.

[40] McKiernan, K.A., Kaufman, J.N., Kucera-Thompson, J., and Binder, J.R. A Parametric Manipulation of Factors Affecting Task-Induced Deactivation in Functional Neuroimaging. Journal of Cognitive Neuroscience 15, 3 (2003), 394-408.

[41] Mooneyham, B.W. and Schooler, J.W. The Costs and Benefits of Mind-wandering: A Review. Canadian Journal of Experimental Psychology / Revue Canadienne De Psychologie Experimentale 67, 1 (2013), 11-18.

[42] Mrazek, M.D., Phillips, D.T., Franklin, M.S., Broadway, J.M., and Schooler, J.W. Young and Restless: Validation of the Mind-Wandering Questionnaire (MWQ) Reveals Disruptive Impact of Mind-wandering for Youth. Frontiers in Psychology 4, (2013), 1-7.

[43] Petter, S., DeLone, W., and McLean, E.R. Information Systems Success: The Quest for the Independent Variables. Journal of Management Information Systems 29, 4 (2013), $7-62$.

[44] Posner, M.I. and Petersen, S.E. The Attention System of the Human Brain. Annual Review of Neuroscience 13, (1990), 25-42.

[45] Raichle, M.E. and Snyder, A.Z. A Default Mode of Brain Function: a Brief History of an Evolving Idea. NeuroImage 37, 4 (2007), 1083-1090; discussion 1097-1099.

[46] Riedl, R., Davis, F.D., Banker, R., and H. Kenning, P. Neuroscience in Information Systems Research. Springer International Publishing, Cham, 2017.

[47] Rossi, P.H. and Nock, S.L., eds. Measuring Social Judgments: the Factorial Survey Approach. Sage Publications, Beverly Hills, 1982.

[48] Sayette, M.A., Dimoff, J.D., Levine, J.M., Moreland, R.L., and Votruba-Drzal, E. The Effects of Alcohol and Dosage-set on Risk-seeking Behavior in Groups and Individuals. Psychology of Addictive Behaviors / Journal of the Society of Psychologists in Addictive Behaviors 26, 2 (2012), 194-200.

[49] Schooler, J.W. Re-representing Consciousness: Dissociations Between Experience and Meta-consciousness. Trends in Cognitive Sciences 6, 8 (2002), 339-344. 
[50] Schooler, J.W., Smallwood, J., Christoff, K., Handy, T.C., Reichle, E.D., and Sayette, M.A. Meta-awareness, Perceptual Decoupling and the Wandering Mind. Trends in Cognitive Sciences 15, 7 (2011), 319-326.

[51] Seli, P., Risko, E.F., Smilek, D., and Schacter, D.L. Mind-Wandering With and Without Intention. Trends in Cognitive Sciences 20, 8 (2016), 605-617.

[52] Smallwood, J. Distinguishing How from Why the Mind Wanders: a Process-Occurrence Framework for Selfgenerated Mental Activity. Psychological Bulletin 139, 3 (2013), 519-535.

[53] Smallwood, J., Fishman, D.J., and Schooler, J.W. Counting the Cost of an Absent Mind: Mind wandering as an Underrecognized Influence on Educational Performance. Psychonomic Bulletin \& Review 14, 2 (2007), 230-236.

[54] Smallwood, J., O'Connor, R.C., Sudbery, M.V., and Obonsawin, M. Mind-wandering and Dysphoria. Cognition and Emotion 21, 4 (2007), 816-842.

[55] Smallwood, J., Schooler, J., Schooler, J., and Schooler, J. The Science of Mind Wandering: Empirically Navigating the Stream of Consciousness. Annual Review of Psychology 66, (2015), 487-518.

[56] Smallwood, J. and Schooler, J.W. The Restless Mind. Psychological Bulletin 132, 6 (2006), 946-958.

[57] Smeekens, B.A. and Kane, M.J. Working Memory Capacity, Mind Wandering, and Creative Cognition: An Individual-Differences Investigation into the Benefits of Controlled Versus Spontaneous Thought. Psychology of Aesthetics, Creativity, and the Arts 10, 4 (2016), 389-415.

[58] Smith, S.M., Fox, P.T., Miller, K.L., et al. Correspondence of the Brain's Functional Architecture During Activation and Rest. Proceedings of the National Academy of Sciences of the United States of America 106, 31 (2009), 13040-13045.

[59] Soror, A.A., Hammer, B.I., Steelman, Z.R., Davis, F.D., and Limayem, M.M. Good Habits Gone Bad: Explaining Negative Consequences Associated with the Use of Mobile Phones from a Dual-systems Perspective. Information Systems Journal 25, 4 (2015), 403-427.

[60] Speier, C., Vessey, I., and Valacich, J. The Effects of Interruptions, Task Complexity, and Information Presentation on Computer-Supported Decision-Making Performance. Decision Sciences 34, t (2003), 771-797.

[61] Sullivan, Y., Davis, F., and Koh, C. Exploring Mind Wandering in a Technological Setting. Proceedings of the Thirty Sixth International Conference on Information Systems, (2015).
[62] Sun, H., Fang, Y., and Zou, H.M. Choosing a Fit Technology: Understanding Mindfulness in Technology Adoption and Continuance. Journal of the Association for Information Systems 17, 6 (2016), 377-412.

[63] Thatcher, J.B., Wright, R., Sun, H., Zagenczyk, T., and Klein, R. Mindfulness in Information Technology Use: Three Empirical Studies. MIS Quarterly forthcoming, (2017).

[64] Turel, O. and Serenko, A. Is Mobile Email Addiction Overlooked? Communications of the Association for Computing Machinery 53, 3 (2010), 41-43.

[65] Turel, O. and Serenko, A. The Benefits and Dangers of Enjoyment with Social Networking Websites. European Journal of Information Systems 21, 5 (2012), 512-528.

[66] Turel, O., Serenko, A., and Bontis, N. Family and Work-related Consequences of Addiction to Organizational Pervasive Technologies. Information \& Management 48, 2-3 (2011), 88-95.

[67] Turel, O., Serenko, A., and Giles, P. Integrating Technology Addiction and Use: An Empirical Investigation of Online Auction Users. MIS Quarterly 35, 4 (2011), 10431061.

[68] Vance, A., Benjamin Lowry, P., and Eggett, D. Increasing Accountability Through User-Interface Design Artifacts: A New Approach to Addressing the Problem of Access-Policy Violations. MIS Quarterly 39, 2 (2015), 345A18.

[69] Venkatesh, V., Thong, J.Y.L., and Xin, X. Unified Theory of Acceptance and Use of Technology: A Synthesis and the Road Ahead. Journal of the Association for Information Systems 17, 5 (2016), 328-376.

[70] Wati, Y., Koh, C., and Davis, F. Can You Increase Your Performance in a Technology-Driven Society Full of Distractions? Proceedings of the Thirty Fifth International Conference on Information Systems, (2014).

[71] Wu, J. and Lu, X. Effects of Extrinsic and Intrinsic Motivators on Using Utilitarian, Hedonic, and Dual-Purposed Information Systems: A Meta-Analysis. Journal of the Association for Information Systems 14, 3 (2013), 153.

[72] Yun, H., Kettinger, W.J., and Lee, C.C. A New Open Door: The Smartphone's Impact on Work-to-Life Conflict, Stress, and Resistance. International Journal of Electronic Commerce 16, 4 (2012), 121-152.

[73] Zhang, Y. and Kumada, T. Relationship Between Workload and Mind-wandering in Simulated Driving. PLOS ONE 12, 5 (2017), e0176962. 


\section{Appendix A}

\section{A1 Gaming (scenario 1)}

To simulate the use of a game, we used the mobile game "Froggy Jump". The main objective is to navigate a frog and jump as high as possible. The higher you get the more points you score. Screenshots from the short movie is shown in Figure 2.

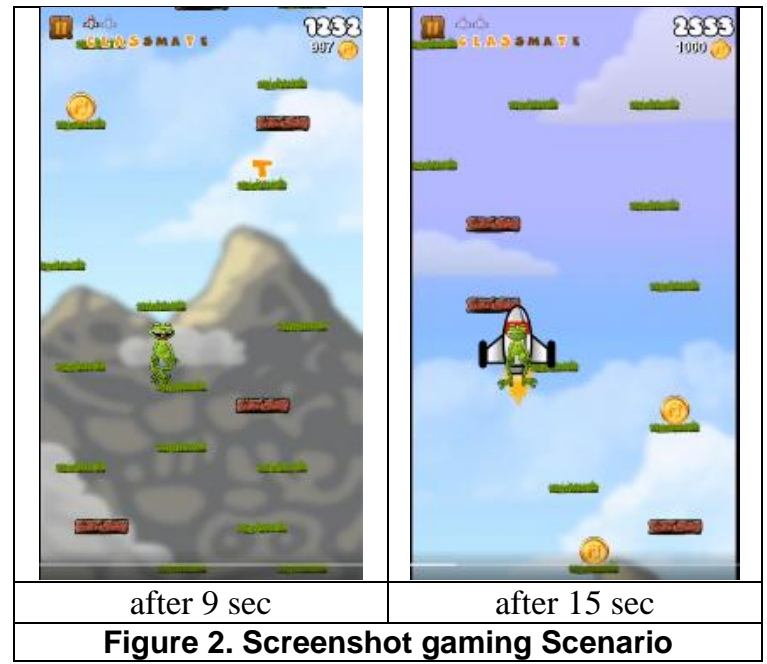

\section{Facebook (scenario 2)}

Facebook was used to simulate social network use because it is widely used and offers a great variety of additional resources that can be queried by the user. The main objective was to simulate a user who goes over several pages (e.g., shopping pages, holiday pages, etc.). Screenshots of three different point that represent the movie are illustrated in the following Figure (c.f. Figure 3).

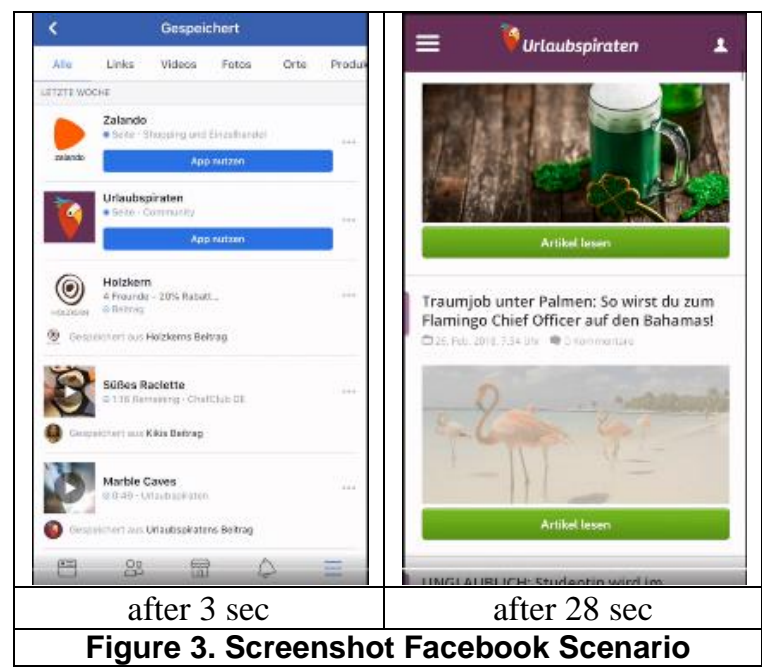

\section{Booking (scenario 3)}

To mimic utilitarian use, we provided a booking process in a national railway company. The movie covered all important phases of a booking process: choosing a date, select an appropriate connection, and finally pay the ticket.

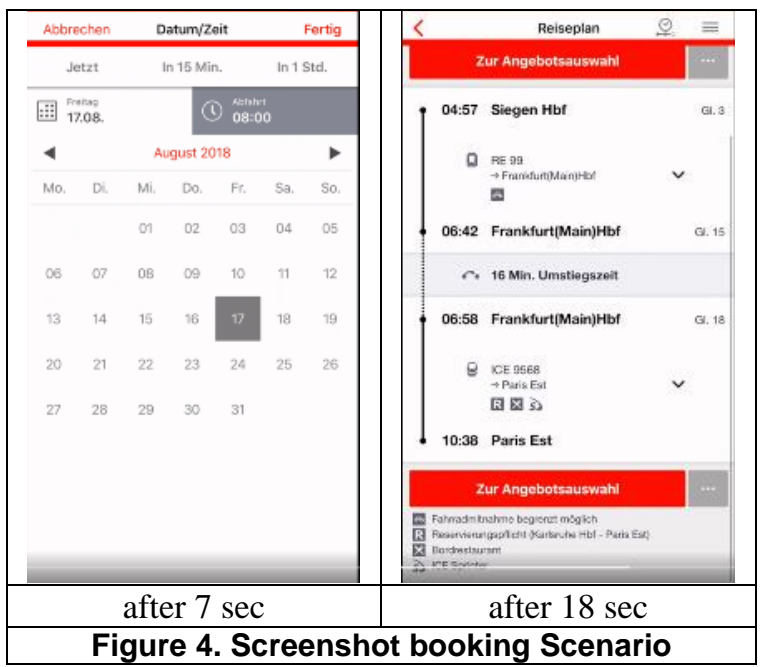

\section{E-Mail (scenario 4)}

A second utilitarian vignette was designed that shows composition and sending of an E-mail. To mimic a utilitarian context, a university professor was chosen as a recipient. An excerpt of the movie is shown in the following figure (c.f. Figure 5).

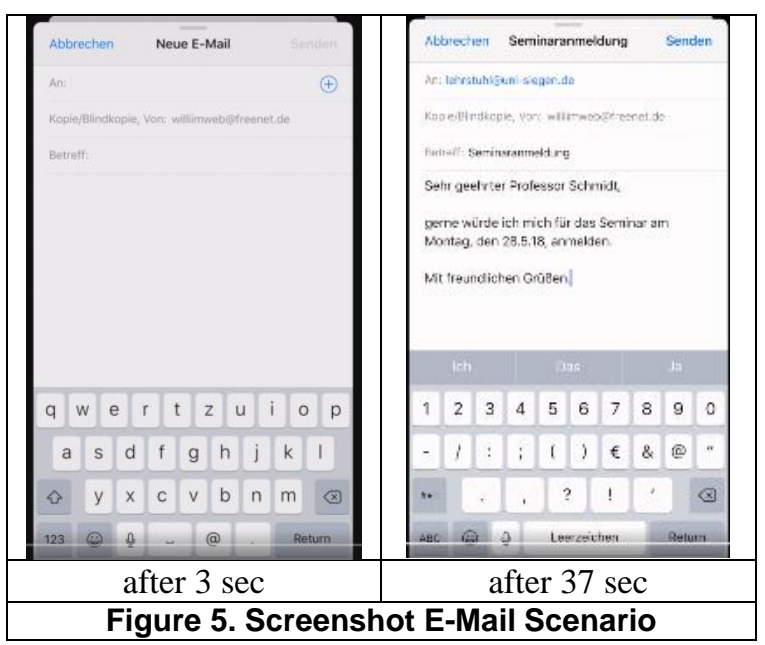

